\title{
In Silico Prediction of the Toxic Potential of Neuroprotective Bifunctional Molecules Based on Chiral N-Propargyl-1,2-amino Alcohol Derivatives
}

Eva Ramos, Rocío Lajarín-Cuesta, Raquel L. Arribas, Eva M. García-Frutos, Laura González-Lafuente, Javier Egea, Cristóbal de los Ríos,* and Alejandro Romero*

Cite This: Chem. Res. Toxicol. 2021, 34, 1245-1249

Read Online

ABSTRACT: N-Propargylamines are useful synthetic scaffolds for the synthesis of bioactive molecules, and in addition, they possess important pharmacological activities. We obtained several neuroprotective molecules, chiral 1,2-amino alcohols and 1,2-diamines, able to reduce by almost $70 \%$ the rotenone and oligomycin A-induced damage in SH-SY5Y cells. Furthermore, some molecules assessed also counteracted the toxicity evoked by the Ser/Thr phosphatase inhibitor okadaic acid. Before extrapolating these data to preclinical studies, we analyze the molecules through an in silico prediction system to detect carcinogenicity risk or other toxic effects. In light of these promising results, these molecules may be considered as a lead family of neuroprotective and relatively safe compounds.

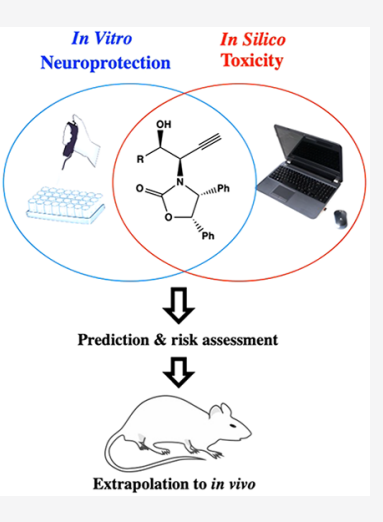

$N$-Propargylamines and $N$-propargylamides are synthetic scaffolds widely used by organic chemistry for the preparation of complex bioactive compounds, ${ }^{1}$ such as 1,2-amino alcohols, ${ }^{2}$ $\beta$-amino acids, ${ }^{3}$ or polyhydroxylated heterocycles, ${ }^{4}$ among others. In this context, we notice that some contributions in the literature report that the $\mathrm{N}$-propargylamine moiety possesses some biochemical activities involved in controlling the cellular redox state, mainly by inhibiting nitric oxide synthase enzymes. ${ }^{5}$ Reportedly, these molecules were demonstrated to be involved in protein kinase C (PKC) and MAPK activation, ${ }^{6,7}$ inhibition of monoamine oxidases (MAO) ${ }^{8}$ or cysteine proteases, ${ }^{9}$ and induction of neurotrophic factors. ${ }^{10}$ Thus, $N$-propargylamine substructures appear in many drugs with neuroprotective properties used for central nervous system diseases. Some examples are the marketed drugs rasagiline $^{7}$ or selegiline ${ }^{11}$ and the drug candidate for Parkinson's disease treatment, ladostigil ${ }^{12,13}$ (Figure 1); nevertheless, they are also studied for Alzheimer's disease (AD) and depression. ${ }^{14}$

Recently, we have described several compounds bearing the $\mathrm{N}$-propargylamine substructure, which demonstrated relevant inhibitory action on MAO-A, ${ }^{15} \mathrm{MAO}-\mathrm{B},{ }^{16}$ or acetylcholinesterase, ${ }^{17}$ as well as a neuroprotective profile. ${ }^{18}$ As a part of a multitarget approach to developing new potential drugs for the treatment of neurodegenerative diseases, Youdim and coworkers designed multifunctional compounds bearing the $\mathrm{N}$ propargylamine moiety together with a 1,2-amino alcohol substructure, and the lead compound was M-30 (Figure 1). ${ }^{19}$ It showed antioxidant properties, regulatory activity of the amyloid precursor protein processing, PKC and MAPK signaling pathway modulation, as well as the induction of neurotrophic factors. ${ }^{20}$

Indeed, 1,2-amino alcohols have been studied as potential drugs for neurodegenerative diseases due to their role in regulating brain metal concentrations, which are altered in $\mathrm{AD}$ patients and involved in the acceleration of the $\beta$-amyloidinduced neuronal damage. ${ }^{21}$ These observations prompted us to hypothesize that homopropargylic compounds, conveniently transformed to present a potentially bioactive $N$-propargylamide moiety linked to a chiral 1,2-amino alcohol, would afford interesting pharmacodynamic and pharmacokinetic properties. Therefore, the prediction of the toxic potential and the evaluation of the neuroprotective profile of a series of deprotected $\beta$-hydroxy- $N$-propargylamides will give us clues to achieve additional chemical designs that will lead us to obtain optimized drugs in this field.

We use in silico predictions to assess the toxicity and cytochrome P450 isoform 3A4 metabolism of the compounds with Toxtree software $\mathrm{v} 3$ 3.1.0. $^{22}$ Based on their structural information, the six compounds were classified as class III

Special Issue: Neurotoxicology

Received: December 11, 2020

Published: February 26, 2021 


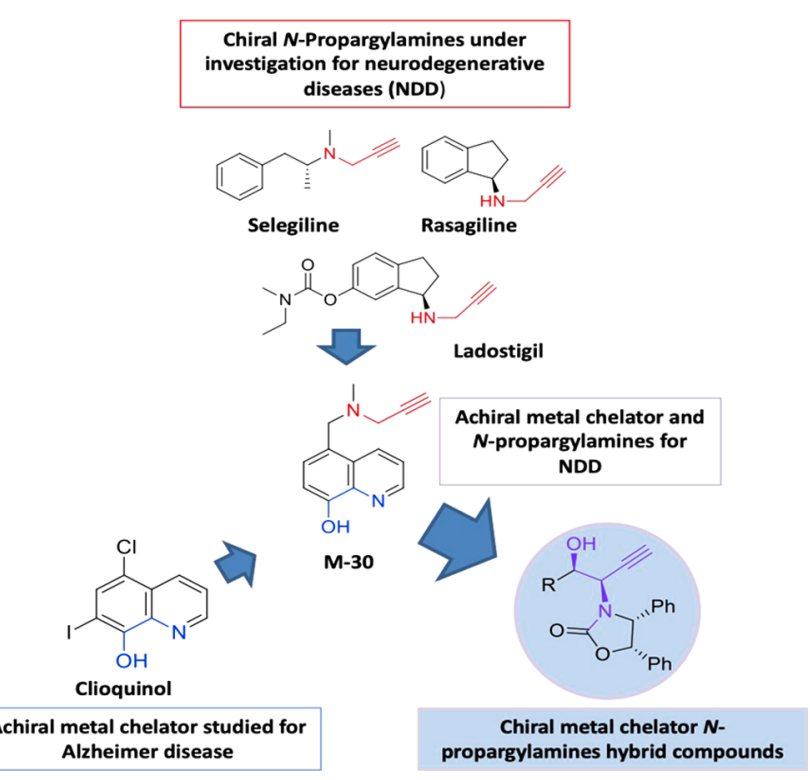

Figure 1. Selected $N$-propargylamines and metal chelators of therapeutic interest, together with the design of the molecules described herein (in color, the potential bioactive moiety).

substances by the Cramer principles, suggesting that there is no strong initial presumption of safety or even significant toxicity with reactive functional groups because of the heterocyclic structure detected. As shown in Table 1, no skin or eye corrosion was estimated to any compound. A preliminary screening of potentially in vivo mutagens, Toxtree fired alkyl carbamate and thiocarbamate structure alert for the S. typhimurium mutagenicity Ames test (in vitro). There was at least one structural alert for the micronucleus assay found, classifying compounds as Class I substances. In the carcinogenicity and mutagenicity discriminant analysis, there was nongenotoxic carcinogenicity, whether it fired a structural alert for genotoxic carcinogenicity (Alkyl carbamate and thiocarbamate structure).

Finally, each of the six compounds results in a class 2 persistent chemical due to its more than two rings. However, further experiments need to be developed to test whether these alerts certainly happen.

Then, to test whether these compounds are not toxic, we use reliable in vitro models, SH-SY5Y cells, which are used to study neuronal function and neurodegenerative diseases.
The preparation of the compounds was accomplished according to what was previously described (Schemes S1 and S2, Supporting Information). ${ }^{23}$ Trimethylsilane (TMS)protected $\mathrm{N}$-propargylamides $\mathbf{2 a}-\mathbf{e}$ and $\mathbf{5}$ were treated with tetrabutylammonium fluoride, which removes the TMS group. Thereby, it furnished compounds $\mathbf{3 a}-\mathbf{e}$ and $\mathbf{6}$ in good yields (Supporting Information), resulting in spectroscopic and analytical data according to their structure (NMR spectra and analytical characterization in Supporting Information).

Obtained results reveal that only molecule $3 \mathrm{~d}$ slightly affected the cell viability, as shown in Figure 2. Subsequently,
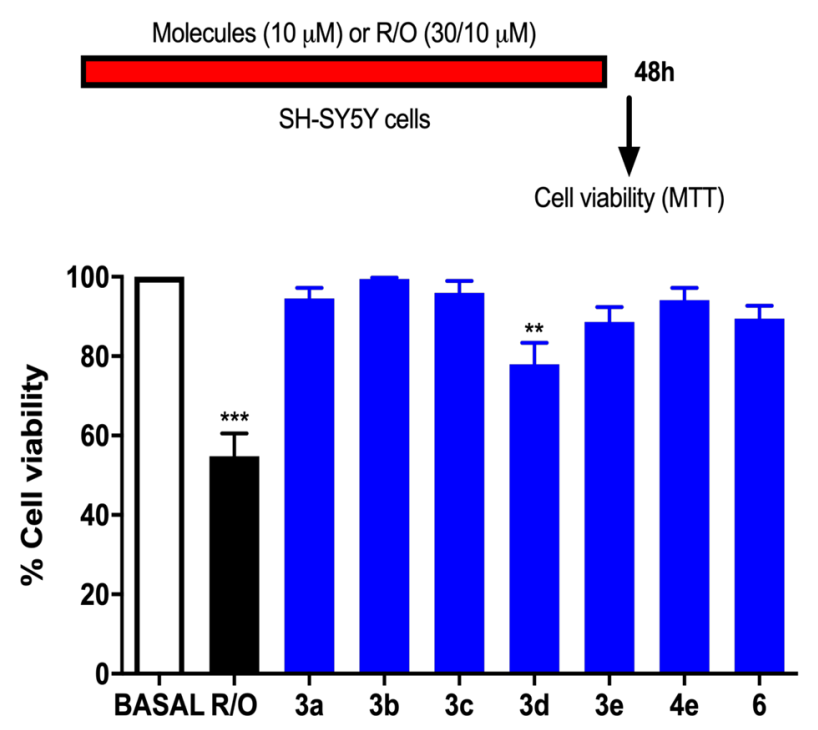

Figure 2. Effect of compounds on SH-SYSY cell viability. Basal bar corresponds to SH-SY5Y neuroblastoma cells only treated with culture medium. In each independent experiment, a batch of cells was treated with the toxic cocktail rotenone and oligomycin A (30 and 10 $\mu \mathrm{M}$, respectively, $\mathrm{R} / \mathrm{O}$ ) as an example of the expected loss of cell viability elicited by a toxic stimulus. Data are means \pm SEM of triplicates of at least five different cell cultures: $* * * p<0.001$ and $* * p$ $<0.01$ with respect to basal.

the neuroprotective profile of compounds $3 a-e, 4 e$, and 6 was evaluated with two toxic stimuli, $30 \mu \mathrm{M}$ rotenone and $10 \mu \mathrm{M}$ oligomycin A (R/O), which inhibit complexes I and V of the mitochondrial electron transport chain, respectively, in $\mathrm{SH}$ SY5Y cells, conditions that result in the generation of reactive oxygen species (ROS) and impair the ATP synthesis. Thus,

\section{Table 1. In Silico Toxicity Assessment for Each Compound}

\begin{tabular}{|c|c|c|c|}
\hline & & $3 a-e$ & 6 \\
\hline 1 & Cramer rules/Cramer rules with extensions & class high (class III) & class high (class III) \\
\hline 2 & skin irritation and corrosion prediction & not corrosive to skin & not corrosive to skin \\
\hline 3 & eye irritation and corrosion prediction & not skin corrosion R34 or R35 & not skin corrosion $\mathrm{R} 34$ or $\mathrm{R} 35$ \\
\hline 4 & skin sensitization reactivity domain alerts & alert for acyl transfer agent identified & alert for acyl transfer agent identified \\
\hline 5 & START biodegradation and persistence plug-in & class 2 (persistent chemical) & class 2 (persistent chemical) \\
\hline 6 & structure alerts for the in vivo micronucleus assay (rodents) & class I & class I \\
\hline 7 & in vitro mutagenicity (Ames test) alerts by ISS & $\begin{array}{l}\text { structural alert for } S \text {. typhimurium } \\
\text { mutagenicity }\end{array}$ & $\begin{array}{l}\text { structural alert for } S \text {. typhimurium } \\
\text { mutagenicity }\end{array}$ \\
\hline 8 & $\begin{array}{l}\text { carcinogenicity (genotoxic and nongenotoxic) and mutagenicity } \\
\text { rulebase by ISS }\end{array}$ & $\begin{array}{l}\text { structural alert for genotoxic } \\
\text { carcinogenicity }\end{array}$ & $\begin{array}{l}\text { structural alert for genotoxic } \\
\text { carcinogenicity }\end{array}$ \\
\hline \multirow{3}{*}{9} & \multirow{3}{*}{ DNA binding alerts } & negative for nongenotoxic carcinogenicity & negative for nongenotoxic carcinogenicity \\
\hline & & alert for SN1 & alert for SN1 \\
\hline & & alert for Michael Acceptor & alert for Michael acceptor \\
\hline
\end{tabular}


cells are in an oxidative stress environment, typically found in several neurodegenerative diseases. As shown in Table 2, when

Table 2. Percent Cell Viability Was Assessed in the Culture of SH-SY5Y Neuroblastoma Cells after the Addition of Molecule 3, 4e, or 6 under the Conditions of Toxicity Exerted by the Stressor Cocktail of $30 \mu \mathrm{M}$ Rotenone and 10 $\mu \mathrm{M}$ Oligomycin A $(\mathrm{R} / \mathrm{O})$ or the Hyperphosphorylating Agent Okadaic Acid (OA, $15 \mathrm{nM})^{a}$<smiles>C#CC(C(O)P)N1C(=O)OC(c2ccccc2)[C@H]1c1ccccc1</smiles><smiles>C#CC(C(c1ccccc1)N(Cc1ccccc1)C(C)=O)N1C(=O)OC(c2ccccc2)[C@H]1c1ccccc1</smiles>

6

\begin{tabular}{llll} 
compound & \multicolumn{1}{c}{$\mathrm{R}$} & \multicolumn{1}{c}{$\mathrm{R} / \mathrm{O}$} & \multicolumn{1}{c}{$\mathrm{OA}$} \\
control & & $63 \pm 3$ & $62 \pm 7^{*}$ \\
memantine & & $\mathrm{nd}$ & $95 \pm 3^{* * *}$ \\
melatonin & & $75 \pm 3^{* *}$ & $\mathrm{nd}$ \\
3a & $\mathrm{Bn}$ & $71 \pm 5^{* *}$ & $91 \pm 5^{* *}$ \\
3b & cyclohexyl & $71 \pm 3^{*}$ & $91 \pm 6^{* *}$ \\
3c & $(S)-\mathrm{CH}(\mathrm{Me}) \mathrm{Ph}$ & $72 \pm 6^{\mathrm{ns}}$ & $50 \pm 4^{\mathrm{ns}}$ \\
3d & $\mathrm{CHPh}$ & $76 \pm 2^{* *}$ & $95 \pm 3^{* * *}$ \\
$3 \mathbf{e}$ & $(R)-\mathrm{CH}(\mathrm{Me}) \mathrm{OPMB}$ & $72 \pm 3^{*}$ & $89 \pm 6^{* *}$ \\
$4 \mathrm{e}$ & $(R)-\mathrm{CH}(\mathrm{Me}) \mathrm{OH}$ & $74 \pm 5^{*}$ & $87 \pm 8^{* *}$ \\
$\mathbf{6}$ & & $73 \pm 3^{*}$ & $61 \pm 12^{\mathrm{ns}}$
\end{tabular}

${ }^{a}$ Cell viability was measured with the method of the MTT reduction, and molecules were tested at $0.3 \mu \mathrm{M}$. Data are expressed as a percentage of viability with respect to cells not exposed to toxic stimuli nor compounds, and shown as mean \pm SEM of four different, at least, cell batches in triplicate; $* * * p<0.001$, $* *_{p}<0.01$, and $* p<$ 0.05 , compared with control, i.e., cells only exposed to toxic stimuli ( $\mathrm{R} / \mathrm{O}$ or $\mathrm{OA}$ ) in the absence of compounds.

SH-SY5Y cells were stimulated with the R/O cocktail, their viability, measured by the MTT assay, ${ }^{24}$ was significantly reduced (37\%), and the presence of compounds, tested at 0.3 $\mu \mathrm{M}$, decreased in most cases such loss of cell viability in a significant manner. The best compound was 3d, which maintained the cell viability up to $76 \%$ with respect to a basal situation, similar to the well-known antioxidant drug melatonin used as the standard. ${ }^{25}$

In the second test, we exposed SH-SY5Y cells to $15 \mathrm{nM}$ okadaic acid (OA); this marine biotoxin is a selective inhibitor of phosphoprotein phosphatases, mainly PP1 and PP2A. ${ }^{26}$ Their inhibition results in the hyperphosphorylation of selected biological targets, including tau protein, which in turn leads to its self-aggregation in the so-called neurofibrillary tangles, one of the principal hallmarks of $\mathrm{AD}$. The administration of OA to neuronal cultures is a well-described $\mathrm{AD}$ in vitro model, in which tauopathy is the source of neuronal damage. In this scenario, cells reduced their viability after the incubation with $\mathrm{OA}$ to $38 \%$; the loss of neuron viability was counteracted by the administration of compounds $3 \mathbf{a}, 3 \mathbf{b}, 3 \mathrm{~d}, 3 \mathbf{e}$, or $4 \mathbf{e}$ at $0.3 \mu \mathrm{M}$, analogously to the protection provided by the anti-AD drug memantine. ${ }^{27}$

In summary, five $\mathrm{N}$-propargylamides have shown potential neuroprotective properties against two toxic stimuli related to neurodegeneration at sub-micromolar concentrations. These results prompt us to continue the study of chiral propargylamides as new chemical entities with promising biological activities for the treatment of neurodegenerative diseases.

\section{ASSOCIATED CONTENT}

\section{Supporting Information}

The Supporting Information is available free of charge at https://pubs.acs.org/doi/10.1021/acs.chemrestox.0c00519.

Materials and methods for the preparation of molecules and the pharmacological protocols, elemental and toxicity end point risk assessment for the six compounds, and predicted metabolites with Toxtree $\mathrm{v}$ 3.1.0 (PDF)

\section{AUTHOR INFORMATION}

\section{Corresponding Authors}

Alejandro Romero - Department of Pharmacology and Toxicology, Faculty of Veterinary Medicine, Complutense University of Madrid, 28040 Madrid, Spain; (1) orcid.org/ 0000-0001-5483-4973; Email: manarome@ucm.es

Cristóbal de los Ríos - Health Research Institute, Clinical Pharmacology Service, University Hospital La Princesa and Institute Teófilo Hernando for Drug Discovery, Department of Pharmacology, School of Medicine, Autonomous University of Madrid, 28006 Madrid, Spain; 이이.org/0000-00026456-7589; Email: cristobal.delosrios@inv.uam.es

\section{Authors}

Eva Ramos - Department of Pharmacology and Toxicology, Faculty of Veterinary Medicine, Complutense University of Madrid, 28040 Madrid, Spain; (o orcid.org/0000-00015791-0687

Rocío Lajarín-Cuesta - Health Research Institute, Clinical Pharmacology Service, University Hospital La Princesa and Institute Teófilo Hernando for Drug Discovery, Department of Pharmacology, School of Medicine, Autonomous University of Madrid, 28006 Madrid, Spain

Raquel L. Arribas - Health Research Institute, Clinical Pharmacology Service, University Hospital La Princesa and Institute Teófilo Hernando for Drug Discovery, Department of Pharmacology, School of Medicine, Autonomous University of Madrid, 28006 Madrid, Spain

Eva M. García-Frutos - Materials Science Factory,Instituto de Ciencia de Materiales de Madrid, Consejo Superior de Investigaciones Científicas, 28049 Madrid, Spain; (1) orcid.org/0000-0001-6270-1126

Laura González-Lafuente - Cardiorenal Translational Laboratory, Institute of Research i+12, Hospital Universitario 12 de Octubre, 28041 Madrid, Spain

Javier Egea - Health Research Institute, Clinical Pharmacology Service, University Hospital La Princesa and Institute Teófilo Hernando for Drug Discovery, Department of Pharmacology, School of Medicine, Autonomous University of Madrid, 28006 Madrid, Spain; Molecular

Neuroinflammation and Neuronal Plasticity Research Laboratory, Hospital Universitario Santa Cristina, 28040

Madrid, Spain; 이이.org/0000-0003-4704-3019

Complete contact information is available at:

https://pubs.acs.org/10.1021/acs.chemrestox.0c00519

\section{Author Contributions}

C.D.L.R. and E.M.G.-F. planned and supervised the synthesis of molecules and prepared the final version of the manuscript. A.R. and E.R. performed the in silico toxicological screening of 
molecules, participated in writing/original draft preparation, and critically revised the manuscript. J.E., R.L.-C., R.L.A., and L.G.-L. performed the toxicological experiments in vitro on the SH-SY5Y cell line and analyzed the combined data. All coauthors read and approved the final version of the manuscript.

\section{Funding}

This work was funded by the following grants: Fondo de Investigaciones Sanitarias (FIS) (ISCIII/FEDER) "Miguel Servet" programs (CP10/00531 and CPII19/00005), "Proyectos de Investigación en Salud" (PI19/01724 and PI19/00082), and "Red CIEN" (PI016/09).

\section{Notes}

The authors declare no competing financial interest.

\section{ACKNOWLEDGMENTS}

We thank Prof. Louis S. Hegedus (Colorado State University, Fort Collins, CO, USA) for his critical review and continuous support. We thank the Autonomous University of Madrid for the fellowships to R.L.C. and R.L.A.

\section{ABBREVIATIONS}

MAO, monoamine oxidase; MAPK, mitogen-activated protein kinase; OA, okadaic acid; R/O, rotenone and oligomycin $\mathrm{A}$

\section{REFERENCES}

(1) Ding, C. H., and Hou, X. L. (2011) Catalytic asymmetric propargylation. Chem. Rev. 111 (3), 1914-1937.

(2) Barbazanges, M., Meyer, C., Cossy, J., and Turner, P. (2011) Synthesis of 1,2-amino alcohols by sigmatropic rearrangements of 3(N-tosylamino)allylic alcohol derivatives. Chem. - Eur. J. 17 (16), 4480-4495.

(3) Ranslow, P. B. D., Hegedus, L. S., and De Los Rios, C. (2004) syntheses and reactions of optically active $\alpha$-Aminoallenylstannanes. J. Org. Chem. 69 (1), 105-111.

(4) Achmatowicz, M., and Hegedus, L. S. (2004) Synthesis of 1deoxy-D-galactohomonojirimycin via enantiomerically pure allenylstannanes. J. Org. Chem. 69 (7), 2229-2234.

(5) Fast, W., Levsky, M. E., Marletta, M. A., and Silverman, R. B. (1997) N omega-propargyl-L-arginine and $\mathrm{N}$ omega-hydroxy-N omega-propargyl-L-arginine are inhibitors, but not inactivators, of neuronal and macrophage nitric oxide synthases. Bioorg. Med. Chem. 5 (8), 1601-1608.

(6) Yogev-Falach, M., Amit, T., Bar-Am, O., Weinstock, M., and Youdim, M. B. (2002) Involvement of MAP kinase in the regulation of amyloid precursor protein processing by novel cholinesterase inhibitors derived from rasagiline. FASEB J. 16 (12), 1674-1676.

(7) Youdim, M. B., Maruyama, W., and Naoi, M. (2005) Neuropharmacological, neuroprotective and amyloid precursor processing properties of selective MAO-B inhibitor antiparkinsonian drug, rasagiline. Drugs Today 41 (6), 369-391.

(8) Bar-Am, O., Yogev-Falach, M., Amit, T., Sagi, Y., and Youdim, M. B. (2004) Regulation of protein kinase $C$ by the anti-Parkinson drug, MAO-B inhibitor, rasagiline and its derivatives, in vivo. J. Neurochem. 89 (5), 1119-1125.

(9) Arkona, C., and Rademann, J. (2013) Propargyl amides as irreversible inhibitors of cysteine proteases-a lesson on the biological reactivity of alkynes. Angew. Chem., Int. Ed. 52 (32), 8210-8212.

(10) Weinreb, O., Amit, T., Bar-Am, O., and Youdim, M. B. (2007) Induction of neurotrophic factors GDNF and BDNF associated with the mechanism of neurorescue action of rasagiline and ladostigil: new insights and implications for therapy. Ann. N. Y. Acad. Sci. 1122, 155168.

(11) Riederer, P., and Jellinger, K. (1983) Neurochemical insights into monoamine oxidase inhibitors, with special reference to deprenyl (selegiline). Acta Neurol. Scand. 68, 43-55.
(12) Finberg, J. P. M., and Rabey, J. M. (2016) Inhibitors of MAO-A and MAO-B in Psychiatry and Neurology. Front. Pharmacol. 7, 340.

(13) Youdim, M. B. (2006) The path from anti Parkinson drug selegiline and rasagiline to multifunctional neuroprotective anti Alzheimer drugs ladostigil and M30. Curr. Alzheimer Res. 3 (5), $541-550$.

(14) Amit, T., Bar-Am, O., Mechlovich, D., Kupershmidt, L., Youdim, M. B. H., and Weinreb, O. (2017) The novel multitarget iron chelating and propargylamine drug M30 affects APP regulation and processing activities in Alzheimer's disease models. Neuropharmacology 123, 359-367.

(15) Bolea, I., Juárez-Jiménez, J., de Los Ríos, C., Chioua, M., Pouplana, R., Luque, F. J., Unzeta, M., Marco-Contelles, J., and Samadi, A. (2011) Synthesis, biological evaluation, and molecular modeling of donepezil and $\mathrm{N}$-[(5-(benzyloxy)-1-methyl-1H-indol-2yl)methyl]-N-methylprop-2-yn-1-amine hybrids as new multipotent cholinesterase/monoamine oxidase inhibitors for the treatment of Alzheimer's disease. J. Med. Chem. 54 (24), 8251-8270.

(16) Samadi, A., de los Ríos, C., Bolea, I., Chioua, M., Iriepa, I., Moraleda, I., Bartolini, M., Andrisano, V., Gálvez, E., Valderas, C., Unzeta, M., and Marco-Contelles, J. (2012) Multipotent MAO and cholinesterase inhibitors for the treatment of Alzheimer's disease: synthesis, pharmacological analysis and molecular modeling of heterocyclic substituted alkyl and cycloalkyl propargyl amine. Eur. J. Med. Chem. 52, 251-262.

(17) Samadi, A., Chioua, M., Bolea, I., de Los Ríos, C., Iriepa, I., Moraleda, I., Bastida, A., Esteban, G., Unzeta, M., Gálvez, E., and Marco-Contelles, J. (2011) Synthesis, biological assessment and molecular modeling of new multipotent $\mathrm{MAO}$ and cholinesterase inhibitors as potential drugs for the treatment of Alzheimer's disease. Eur. J. Med. Chem. 46 (9), 4665-4668.

(18) Samadi, A., Valderas, C., de los Ríos, C., Bastida, A., Chioua, M., González-Lafuente, L., Colmena, I., Gandía, L., Romero, A., Del Barrio, L., Martín-De-Saavedra, M. D., López, M. G., Villarroya, M., and Marco-Contelles, J. (2011) Cholinergic and neuroprotective drugs for the treatment of Alzheimer and neuronal vascular diseases. II. Synthesis, biological assessment, and molecular modelling of new tacrine analogues from highly substituted 2-aminopyridine-3-carbonitriles. Bioorg. Med. Chem. 19 (1), 122-133.

(19) Avramovich-Tirosh, Y., Amit, T., Bar-Am, O., Zheng, H., Fridkin, M., and Youdim, M. B. (2007) Therapeutic targets and potential of the novel brain- permeable multifunctional iron chelatormonoamine oxidase inhibitor drug, M-30, for the treatment of Alzheimer's disease. J. Neurochem. 100 (2), 490-502.

(20) Weinreb, O., Mandel, S., Bar-Am, O., Yogev-Falach, M., Avramovich-Tirosh, Y., Amit, T., and Youdim, M. B. (2009) Multifunctional neuroprotective derivatives of rasagiline as antiAlzheimer's disease drugs. Neurotherapeutics 6 (1), 163-174.

(21) Zheng, H., Weiner, L. M., Bar-Am, O., Epsztejn, S., Cabantchik, Z. I., Warshawsky, A., Youdim, M. B., and Fridkin, M. (2005) Design, synthesis, and evaluation of novel bifunctional iron-chelators as potential agents for neuroprotection in Alzheimer's, Parkinson's, and other neurodegenerative diseases. Bioorg. Med. Chem. 13 (3), 773783.

(22) Patlewicz, G., Jeliazkova, N., Safford, R. J., Worth, A. P., and Aleksiev, B. (2008) An evaluation of the implementation of the Cramer classification scheme in the Toxtree software. SAR QSAR Environ. Res. 19 (5-6), 495-524.

(23) de Los Ríos, C., and Hegedus, L. S. (2005) Reaction of optically active alpha-aminoallenylstannanes with aldehydes formed in situ from the Lewis-acid-catalyzed rearrangement of epoxides. J. Org. Chem. 70 (16), 6541-6543.

(24) Denizot, F., and Lang, R. (1986) Rapid colorimetric assay for cell growth and survival. Modifications to the tetrazolium dye procedure giving improved sensitivity and reliability. J. Immunol. Methods 89 (2), 271-277.

(25) Romero, A., Egea, J., García, A. G., and López, M. G. (2010) Synergistic neuroprotective effect of combined low concentrations of 
galantamine and melatonin against oxidative stress in SH-SY5Y neuroblastoma cells. J. Pineal Res. 49 (2), 141-148.

(26) Medina, M., Avila, J., and Villanueva, N. (2013) Use of okadaic acid to identify relevant phosphoepitopes in pathology: a focus on neurodegeneration. Mar. Drugs 11 (5), 1656-1668.

(27) Ma, O. K., and Sucher, N. J. (2004) Molecular interaction of NMDA receptor subunit NR3A with protein phosphatase 2A. NeuroReport 15 (9), 1447-1450. 